CORRESPONDENCE

\title{
Assessment of vitamin C effects on pneumonia and COVID-19 using Mendelian randomization: analysis may be misleading
}

(c) The Author(s), under exclusive licence to Springer Nature Limited 2022

European Journal of Clinical Nutrition (2022) 76:1347-1348; https:// doi.org/10.1038/s41430-022-01091-9

\section{TO THE EDITOR:}

Based on their Mendelian randomization study, Hui et al. concluded that there is no support for the use of vitamin $C$ in the prevention and treatment of pneumonia or COVID-19 [1]. However, their study has limitations.

Hui et al. [1] used single nucleotide polymorphisms (SNPs) that were associated with plasma vitamin $\mathrm{C}$ level in the genome-wide association study in 52,018 people of European ancestry [2]. However, the cited study states "the variance of plasma vitamin $\mathrm{C}$ explained by the 11 lead SNPs was $1.87 \%$ on average" [2]. Explaining such a small proportion of the variance is not a valid measure of the possible effects of vitamin C.

With low dietary vitamin C intakes, plasma levels can fall below $10 \mu \mathrm{M}$, whereas with high dietary intakes, plasma levels can increase to over $80 \mu \mathrm{M}$ (see Fig. $1 \mathrm{C}$ in [3]). It is important to take into account this eightfold range of plasma vitamin $C$ levels when considering the dose-health relationship in the community. Low plasma vitamin C levels are not uncommon. Levels below $11 \mu \mathrm{M}$ were reported, for example, in $25 \%$ of men and $16 \%$ of women from low-income populations in the UK [4], and in $13 \%$ of a US cohort [5]. In less developed countries, where pneumonia is much more prevalent, vitamin C levels are usually lower than in Western countries $[6,7]$. Finally, severe diseases such as pneumonia can alter vitamin $C$ metabolism and can temporarily decrease plasma vitamin $C$ levels to below $10 \mu \mathrm{M}[8,9]$.

Scurvy, as a result of severe vitamin $C$ deficiency, has been directly linked to pneumonia $[6,8]$. It therefore seems likely that less severe vitamin $C$ deficiency may also increase the risk of pneumonia, in which case the most appropriate comparison is between low and high plasma levels, e.g., 10-20 $\mu \mathrm{M}$ vs. $60-100 \mu \mathrm{M}$. If a study compares small variations within the high intake range only, the comparison is uninformative about possible effects of vitamin $C$ in the low intake range.

Although it is fundamentally essential in a vitamin $C$ study to know which levels of the vitamin are being compared, Hui et al. did not state what they considered to be low and high vitamin C levels [1]. We estimate the average difference in plasma vitamin $C$ levels explained by the selected SNPs as follows. Over the included cohorts covering the 52,018 people [2], the mean vitamin C plasma level was $50 \mu \mathrm{M}$, with a SD of $20 \mu \mathrm{M}$. The latter corresponds to a variance of $400 \mu \mathrm{M}^{2} ; 1.87 \%$ of such a variance is $7.5 \mu \mathrm{M}^{2}$, and SD is then $2.7 \mu \mathrm{M}$. Thus, statistically the analysis by Hui et al. corresponds to the comparison of two population groups of equal size with vitamin C levels of 47.3 vs. $52.7 \mu \mathrm{M}$ (see calculation in the Supplementary file). This is not clinically meaningful when an examination of vitamin $C$ and pneumonia should ideally compare plasma levels between 10-20 $\mu \mathrm{M}$ and 60-100 $\mu \mathrm{M}$.

Three small controlled trials reported significantly lower pneumonia incidence in vitamin $C$ groups, but the contexts were very specific and thus the findings cannot be extrapolated to the general population $[6,8]$. One was with school children during WW-II with documented very low vitamin C intake, another with US Marines during physically heavy recruit training, and the third with influenza A patients. In all these trials, the incidence of pneumonia in the control group was much higher than in Western countries currently $[6,8]$. The three small trials have shortcomings, but nevertheless, Mendelian randomization analysis of adults in the general population is not comparable with the findings from these three trials in very specific populations.

Furthermore, severe diseases such as pneumonia can decrease plasma vitamin $C$ levels, with the decline in level correlated with disease severity $[8,9]$. Hui et al. do not provide any evidence of the selected SNPs correlating with the decreased vitamin $C$ levels of sick people. Their study does not offer any information about possible treatment effects of vitamin C for pneumonia or COVID19 , despite the claims otherwise. There are randomized trial data indicating that treatment with vitamin $C$ may have effects on severe infections in some contexts. A re-analysis of the CITRIS-ALI trial showed that during the intervention period vitamin $C$ reduced mortality due to sepsis by $81 \%$ (95\% Cl 45-94\%) [10], and a re-analysis of the COVID A to Z trial showed that vitamin C increased the rate of recovery of COVID-19 patients [11]. These treatment effects cannot be investigated using weak genetic correlations. Randomized trials are needed for conclusive evidence.

Harri Hemilä ${ }^{1 D^{凶}}$ and Elizabeth Chalker $\mathbb{D}^{2 \bowtie}$

${ }^{1}$ Department of Public Health, University of Helsinki, POB 20, Helsinki, FI 00014, Finland. ${ }^{2}$ Biological Data Science Institute, Australian National University, Canberra, ACT 2601, Australia. 凶email: harri.hemila@helsinki.fi; elizabeth.chalker@gmail.com

\section{REFERENCES}

1. Hui LL, Nelson EAS, Lin SL, Zhao JV. The role of vitamin C in pneumonia and COVID-19 infection in adults with European ancestry: a Mendelian randomisation study. Eur J Clin Nutr. 2021;30:1-4. https://doi.org/10.1038/s41430-021-00993-4, http://www.ncbi.nlm.nih.gov/pmc/articles/pmc8404179

2. Zheng JS, Luan J, Sofianopoulou E, Imamura F, Stewart ID, Day FR, et al. Plasma vitamin $C$ and type 2 diabetes: genome-wide association study and Mendelian randomization analysis in European populations. Diabetes Care. 2021;44:98-106. https://doi.org/10.2337/dc20-1328, http://www.ncbi.nlm.nih. gov/pmc/articles/pmc7783939

3. Levine M, Conry-Cantilena C, Wang Y, Welch RW, Washko PW, Dhariwal KR, et al. Vitamin $C$ pharmacokinetics in healthy volunteers: evidence for a recommended dietary allowance. Proc Natl Acad Sci USA. 1996;93:3704-9. https://doi.org/ 10.1073/pnas.93.8.3704, http://www.ncbi.nlm.nih.gov/pmc/articles/pmc39676 
4. Mosdøl A, Erens B, Brunner EJ. Estimated prevalence and predictors of vitamin C deficiency within UK's low-income population. J Public Health. 2008;30:456-60. https://doi.org/10.1093/pubmed/fdn076

5. Schleicher RL, Carroll MD, Ford ES, Lacher DA. Serum vitamin C and the prevalence of vitamin C deficiency in the United States: 2003-2004 National Health and Nutrition Examination Survey (NHANES). Am J Clin Nutr. 2009;90:1252-63. https://doi.org/10.3945/ajen.2008.27016

6. Hemilä $H$, Louhiala P. Vitamin C may affect lung infections. J R Soc Med. 2007;100:495-8. https://doi.org/10.1177/014107680710001109, http://www.ncbi. nlm.nih.gov/pmc/articles/pmc2099400

7. Rowe $S$, Carr AC. Global Vitamin C status and prevalence of deficiency: a cause for concern? Nutrients 2020;12:2008. https://doi.org/10.3390/nu12072008, http:// www.ncbi.nlm.nih.gov/pmc/articles/pmc7400810

8. Hemilä $\mathrm{H}$, Louhiala P. Vitamin $\mathrm{C}$ for preventing and treating pneumonia. Cochrane Database Syst Rev. 2013;CD005532. https://doi.org/10.1002/14651858.cd005532.pub3

9. Carr AC, Spencer E, Dixon L, Chambers ST. Patients with community acquired pneumonia exhibit depleted vitamin $C$ status and elevated oxidative stress. Nutrients. 2020;12:1318. https://doi.org/10.3390/nu12051318, http://www.ncbi. nlm.nih.gov/pmc/articles/pmc7284353

10. Hemilä H, Chalker E. Reanalysis of the effect of vitamin C on mortality in the CITRIS-ALI trial: important findings dismissed in the trial report. Front Med. 2020;7:590853. https://doi.org/10.3389/fmed.2020.590853, http://www.ncbi.nlm. nih.gov/pmc/articles/pmc7575729

11. Hemilä $\mathrm{H}$, Carr A, Chalker E. Vitamin $\mathrm{C}$ may increase the recovery rate of outpatient cases of SARS-CoV-2 infection by 70\%: reanalysis of the COVID A to $Z$ rand omized clinical trial. Front Immunol. 2021;12:674681. https://doi.org/10.3389/ fimmu.2021.674681, http://www.ncbi.nlm.nih.gov/pmc/articles/pmc8141621

\section{AUTHOR CONTRIBUTIONS}

$\mathrm{HH}$ carried out the statistical analysis and wrote the draft. EC checked the statistical analyses and participated in the revision of the paper.

\section{COMPETING INTERESTS}

The authors declare no competing interests.

\section{ADDITIONAL INFORMATION}

Supplementary information The online version contains supplementary material available at https://doi.org/10.1038/s41430-022-01091-9.

Correspondence and requests for materials should be addressed to Harri Hemilä or Elizabeth Chalker.

Reprints and permission information is available at http://www.nature.com/ reprints

Publisher's note Springer Nature remains neutral with regard to jurisdictional claims in published maps and institutional affiliations. 